\title{
Open Ended Laboratory (OEL) Assignment as Tool Imparting Generic Skills for Engineering Students
}

\author{
Noorhisham Tan Kofli ${ }^{1,2}$, Syarifah Najiha Badar ${ }^{2}$, Norliza Abd Rahman², Mohd Shahbudin Mastar ${ }^{2} \&$ Siti \\ Rozaimah Sheikh Abdullah ${ }^{1,2}$ \\ ${ }^{1}$ Department of Chemical \& Process Engineering, Faculty of Engineering \& Built Environment, Universiti \\ Kebangsaan Malaysia, Selangor, Malaysia \\ ${ }^{2}$ Center for Engineering Education Research, Faculty of Engineering \& Built Environment, Universiti \\ Kebangsaan Malaysia, Selangor, Malaysia \\ Correspondence: Noorhisham Tan Kofli, Department of Chemical \& Process Engineering, Faculty of \\ Engineering \& Built Environment, Universiti Kebangsaan Malaysia, 43600 UKM Bangi, Selangor, Malaysia. Tel: \\ 60-3-8921-6401. E-mail: maverick@eng.ukm.my
}

Received: September 24, 2012 Accepted: November 7, 2012 Online Published: November 30, 2012

doi:10.5539/ass.v8n16p146

URL: http://dx.doi.org/10.5539/ass.v8n16p146

\begin{abstract}
Generic skills play a vital role in increasing the employability and marketability of a student. As for the Department of Chemical and Process Engineering, UKM, some of these skills are imparted in the assignment given to students called Open Ended Laboratory (OEL). In this OEL assignment, students are required to propose an experiment title based on the general topic given for that particular semester. The students, working in groups of 3 to 4 students, need to determine the objectives, apparatus and methods as well as execute the experiment. A report including results, discussion, conclusion and references is submitted for evaluation. The final presentation of students' work is organised in a competition poster presentation format. Skills such as communication (oral and written), organisation, teamwork, innovation and creativity were evaluated for this assignment. We discovered that these skills can be nurtured by looking at the marks given by the judges and peer assessment matrices.
\end{abstract}

Keywords: open-ended laboratory, generic skills, teamwork, soft skills, innovation and creativity

\section{Introducation}

Generic skills are defined as transferable skills which are essential for employability (Kearns, 2001) is also known as soft skills (Green, 2009) which includes skills such as teamwork, leadership, communication, social and cultural understanding, problem solving, decision making (Giusti, 2008) and those personal attributes to be linked with values and identity (Sanguinetti, 2004). Now, generic skills in students' development have become vital since they are indicators of higher-education success (Chan, 2010), and also they have become attributes that employers favour (Green et al, 2009). Unfortunately, these skills are not easily imparted in an education curriculum since many academicians are not trained in these skills themselves.

Traditional courses do not seem to succeed in helping students to acquire these sorts of skills either as most of them mainly focus on teaching technical content, and lectures are usually organized according to teacher-centred approaches where the teacher plays the role of information dispenser while the students act as passive receptacles (Green, 2009), whereas generic skills are normally obtained mainly through life experiences, learning environment and approach (Barrie, 2006), and arise from their life (Green, 2009), not in the classroom.

One of the ways that can be used to expose students to and train them in these skills is via laboratory courses. The usual traditional approach of handling laboratory courses normally placed emphasis on a group of students running a fixed experiment to learn a concept, principles or laws using a given methodology. The students mainly repeated the experiment using methods normally handed to them. This type of approach is no longer adequate in the recent context of engineering education, especially in an outcome-based education scenario (Norliza et al, 2011). More active learning approaches must be promoted to students, including open-ended assignments, laboratory (Webb, 2007) and virtual laboratory (Domingues et al, 2010). To ensure students are exposed to this type of assignment, the department introduced Open Ended Laboratory (OEL) in 2008 to 
third-year students enrolling in both chemical and biochemical engineering degree programmes. In this new approach, students are required to propose an experiment based on the general topic given for that particular semester. They are required to determine the title, objectives and scope, identify apparatus needed and prepare the methodology, run the experiment and finally submit the reports. Oral presentation is done through a poster presentation session and is judged on the originality of their ideas, teamwork, and their communication skills during the presentation.

By introducing this type of assignment, we hope that students will become actively involved within the groups to achieve the objectives of imparting generic skills such as leadership, communication and teamwork. It should also promote self-learning and self-independence (Noorhisham et al, 2009), and stimulates social interchange that requires the use of soft skills (Thomas et al, 2009). It can also be used as a platform to nurture innovation and creativity in solving engineering problems.

\section{Method}

\subsection{Students}

All students in the third year (around 60 students) enrolled in two programmes offered by the department; the Chemical (KK) and Biochemical (KB) programmes are registered for this laboratory and were firstly divided into groups of three-four students resulting in 19 groups (11 groups for KK and 8 groups for KB).

\subsection{Judges Evaluation}

The judges' evaluation is conducted during the poster session presentation which is organised in a competition style. The marks are given based on knowledge (PO1), communication skills (PO2), creativity and innovation (PO9) and teamwork (PO6). Each judge (normally two) receives a marking template consisting of 21 questions (Table 1) related to these elements using a scale of 1 to 5.

\subsection{Peer Assessment}

The assessment is done using a questionnaire to each group asking them seven questions (Table 2) formulated on their participation during the assignment. The questionnaire is given after the OEL and students are asked to rate their peers based on the Likert scale of 1 to 5 .

\section{Results}

Table 1 lists all the 21 questions a judge requires to rate the students' performance based on their poster session competition. The questions are divided into four main sections which relate to programme outcomes (PO).

Table 1. Assessment elements

\begin{tabular}{ll}
\hline \multicolumn{1}{c}{ Elements } & \multicolumn{1}{c}{ Questions } \\
\hline Knowledge (PO1) & Understanding of theory and concept \\
& Ability to analyse and present the data in appropriate format (tables, figures, \\
graphs) & Understanding of results and conclusion of the experiment \\
Communication/Presentation & Response to comments and questions \\
(PO2) & Ability to express ideas clearly, organised, smooth and appropriate notes \\
(oral) & Ability to express ideas clearly, organised, smooth and appropriate notes \\
& (written) \\
& Concise and attractive posters \\
& Using a standard language \\
& Ability to make deduction (written) concise, precise and consistent \\
& Logical and sound presentation \\
& Confidence and appropriate appearance \\
All members understood the theory/concept of the experiment & Members able to give consistent answers \\
Teamwork (PO6) & Level of cooperation
\end{tabular}


Innovation/Creativity (PO9) Using new ideas in the experiment

Showing creativity

Uniqueness of the experiment

Good scientific background of the experiment

Able to solve the problem in the experiment

Able to draw a conclusion

Figures 1, 2, 3 and 4 depict average marks given by two judges for each group for each section. The average marks for PO1 were $11.5 \%$ for KK and $11.6 \%$ for KB. As for PO2, the average marks were $32 \%$ and $30.3 \%$ for KK and KB respectively. For PO6 the average marks were $12.1 \%(\mathrm{KK})$ and $12.3 \%(\mathrm{~KB})$ and for PO9 the average marks were $25.5 \%(\mathrm{KK})$ and $24.2 \%(\mathrm{~KB})$.

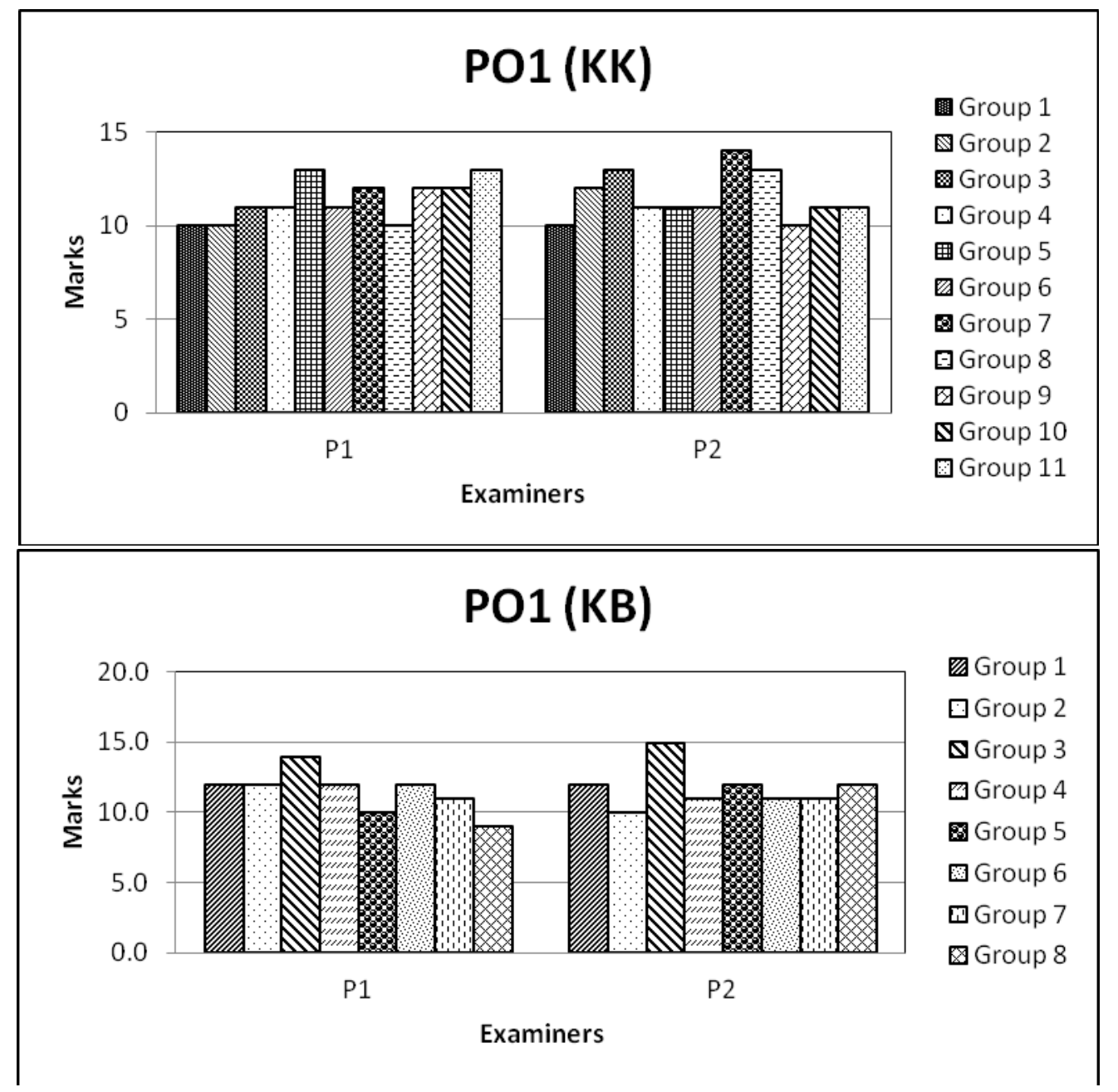

Figure 1. Marks given by the examiner for PO1 achievement for Chemical and Biochemical Engineering Students 

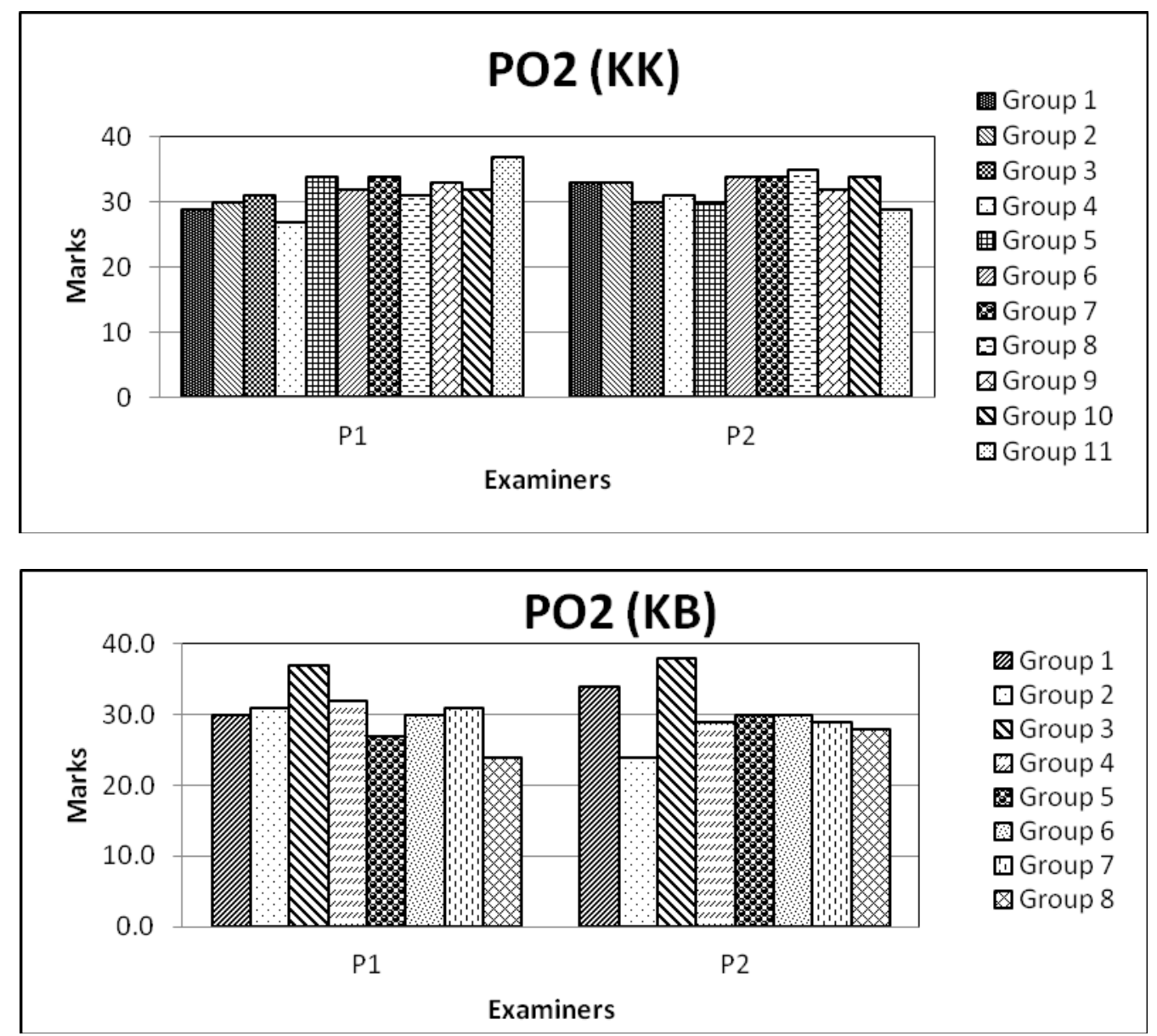

Figure 2. Marks given by the examiner for $\mathrm{PO} 2$ achievement for Chemical and Biochemical Engineering Students

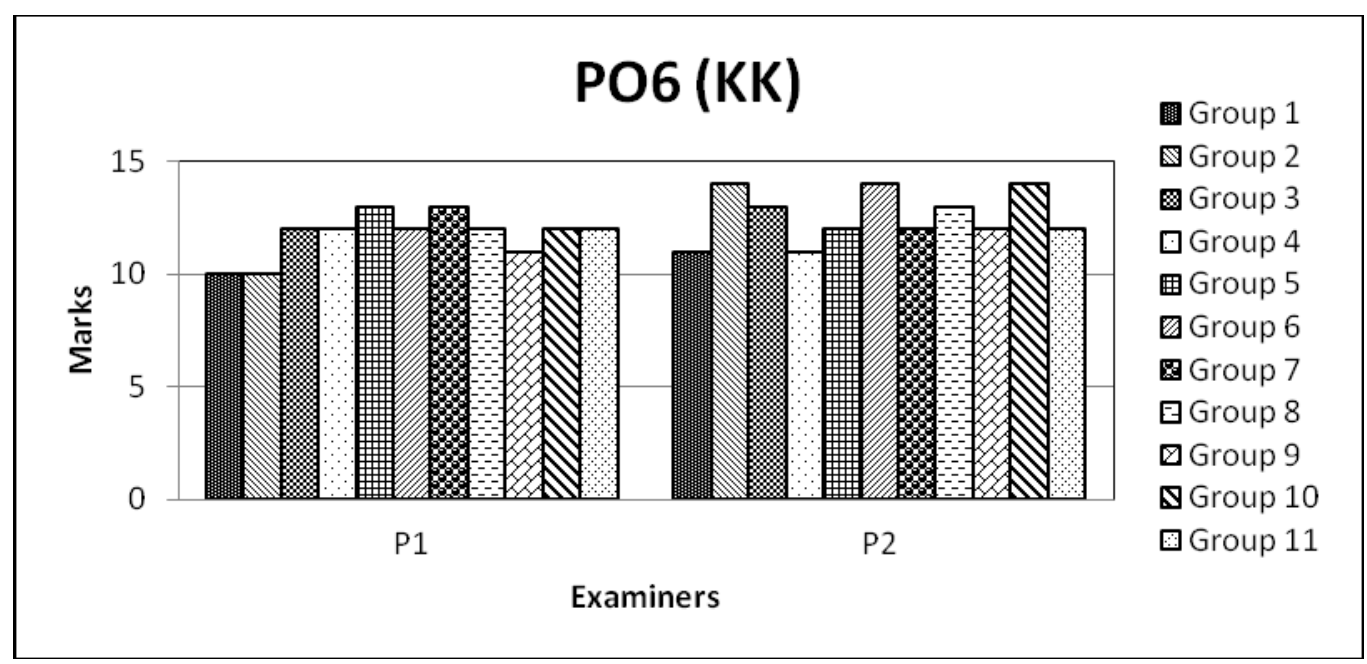




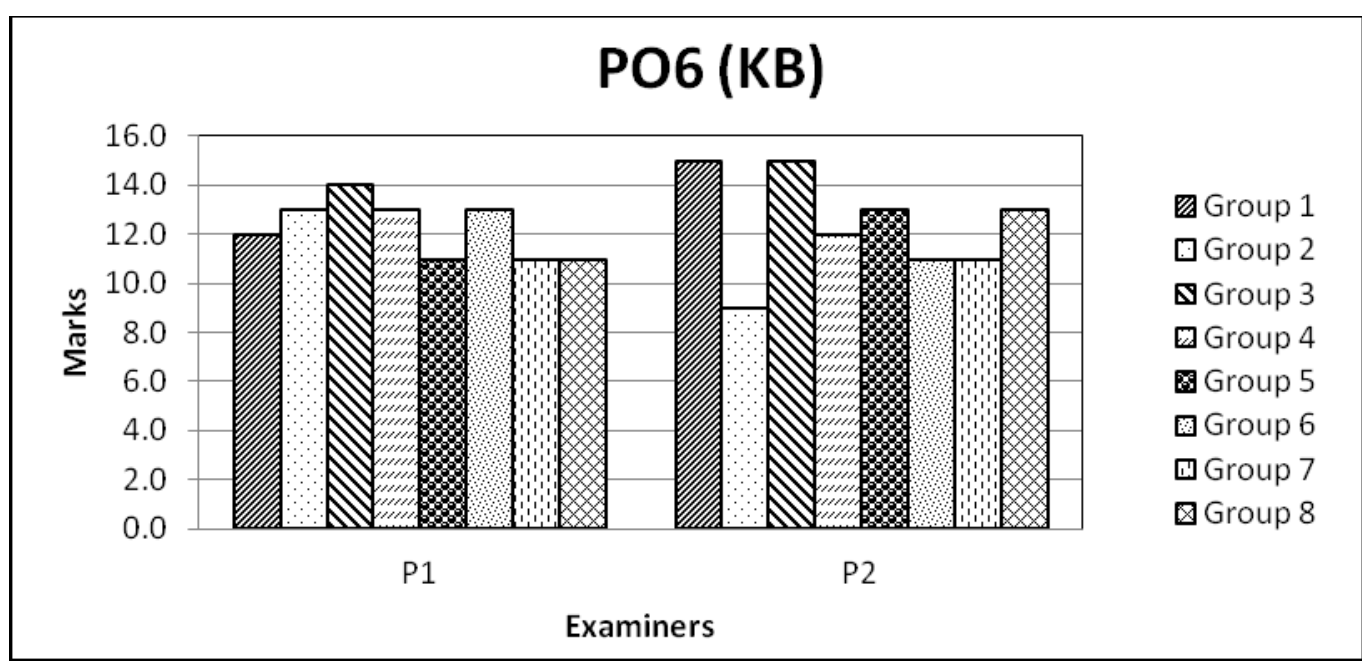

Figure 3. Marks given by the examiner for PO6 achievement for Chemical and Biochemical Engineering Students

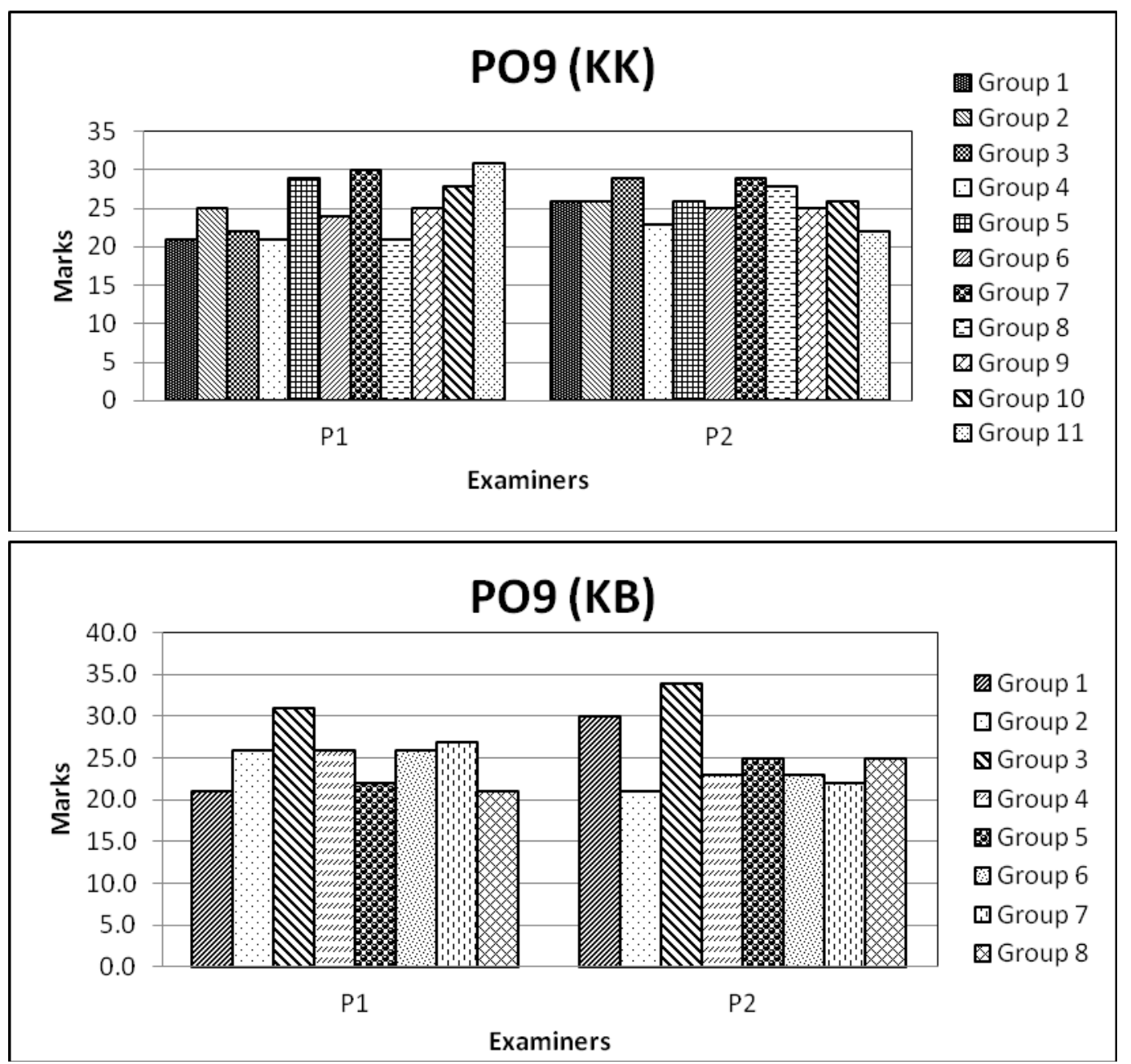

Figure 4. Marks given by the examiner for PO9 achievement for Chemical and Biochemical Engineering Students

\section{Discussion}

Figures 1-4 show example of the results obtained by the groups given by both examiners. As shown in figures, the marks given to all groups for all four components measured were above $70 \%$, indicating students' capability in knowledge and the generic skills assessed such as communication, teamwork, innovation and creativity. The 
highest marks obtained by groups were $95 \%$ and $92.5 \%$ for KK and KB respectively. Since the presentation was executed in a competition format and was not based on the programmes enrolled in, these two groups were also champions and the first runner-up winners. From our observation, they obtained high scores from the examiners due to their excellent posters, managed to relate their problem convincingly and presented a unique laboratory experiment. Thus, we suggested that this assignment had managed to impart the generic skills into students' learning experience by forcing them to run the experiments.

As for creativity and innovation, at least three groups obtained marks slightly above $50 \%$, which resulted from the experiments that they chose and their inability to think outside their comfort zone. Most could not manage to relate their experiment to real problems and were afraid of drawing conclusions from the results that they obtained. Because of this, their presentation was also lacklustre and uninspiring. However, hindrance coming from budget and financial constraints and safety issues can also limit students' innovation and creativity in their experiment selection. In some cases, experiments could not be carried out due to limitations in equipment, expensive chemicals and long completion periods. In general, we observed that most groups managed to come up with innovative experiments, relating them to daily and local problems.

Apart from assessment by the examiners, the students were also assessed on their peer participation and contribution to the assignment using a questionnaire consisting of seven questions (Table 2), again on a scale of 1 to 5. As expected, all students gave full marks to their team members. Though reminded to be honest and sincere in assessing their friends, from our experience not many students dare to give lower marks to uncooperative and non-participating peers for fear of being called 'whistle-blower' or suffering repercussions from their actions (Noorhisham \& Norliza, 2011).

In the comment section, there were few comments recorded on how cooperative their group members were and whether they had worked well together. However, the results discussed here are only for one batch of students. Having dealt with a few batches of students, from our experience we did have students who did not participate well within their groups. As a result, these groups did honestly rate these students as uncooperative and not helpful and thus having minimum teamwork skills. Looking at this issue, peer assessment can be a tool for measuring teamwork and also offer uniquely different and valuable feedback of student performance (Lanning et al, 2011)

Table 2. Peer assessment questions

Questions
Ability to work in group in achieving objectives
Ability to be a leader or follower
Showing respect and open to other people's opinion
Ability to accept variation in group
Showing ability to be involved and contributing to the planning and organising of group work
Responsible
Helpful

In conclusion, we observed that OEL has given students a platform to work within a group to achieve certain objectives imparting generic skills during the assignment. The poster competition session also developed healthy competitiveness amongst groups, creating fun outside classroom activities. We also believe it has fostered and enhanced their generic skills based on the marks obtained.

\section{Acknowledgements}

The authors would like to thank the Universiti Kebangsaan Malaysia for the financial contribution assisting this research through the action research grant (PTS-2011-005) and the operational research grant (OUP-2012-126). This work was supported by the Centre for Engineering Education Research, Faculty of Engineering and Built Environment, Universiti Kebangsaan Malaysia, Bangi, Selangor, Malaysia.

\section{References}

Barrie, S. C. (2006). Understanding what we mean by the generic attributes of graduates. Higher Education, 5l(2), 215-241. http://dx.doi.org/10.1007/s10734-004-6384-7

Chan, W. S. C. (2010). Students' understanding of generic skills development in a university in Hong Kong. 
Procedia Social and Behavioral Sciences, WCES-2010, 2, 4815-4819. http://dx.doi.org/10.1016/j.sbspro.2010.03.776

Domingues, L., Rocha, I., Dourado, F., Alves, M., \& Ferreira, E. C. (2010). Virtual laboratories in (bio) chemical engineering education. Education for Chemical Engineers, 5, e22-e27. http://dx.doi.org/10.1016/j.ece.2010.02.001

El-Farargy, N. (2010). The views, attitudes and learning style preferences of Higher National Chemical Engineering students. Education for Chemical Engineers, 5, e55-e71. http://dx.doi.org/10.1016/j.ece.2010.07.001

Giusti, G. (2008). Soft skills for lawyers. Chelsea Publishing, UK.

Green, F. (2009). The growing importance of generic skills. Article for Beyond Current Horizons Projects, UK. Retrieved from www.beyondcurrenthorizons.uk

Green, W., Hammer, S., \& Star, C. (2009). Facing up to the challenge: Why is it so hard to develop graduate attributes? Higher Education Research \& Development, 28(1), 17-19. http://dx.doi.org/10.1080/07294360802444339

Kearns, P. (2001). Generic skills for the new economy - review of research. NCVER, Adelaide

Lanning, S. K., Brickhouse, T. H., Gunsolley, J. C., Ranson, S. L., \& Willett, R. M. (2011). Communication skills instruction: An analysis of self, peer-group, student instructors and faculty assessment. Patient Education and Counseling, 83, 145-151. http://dx.doi.org/10.1016/j.pec.2010.06.024

Le, K. N., \& Tam, V. W. Y. (2008). On generic skill development: An engineering perspective. Digital Signal Processing, 18, 355-363. http://dx.doi.org/10.1016/j.dsp.2007.04.015

Noorhisham, T. K., \& Norliza A. R. (2011). The open ended laboratory for measurement of communication skills for chemical/biochemical engineering students. Procedia Social and Behavioral Sciences, 18, 65-70. http://dx.doi.org/10.1016/j.sbspro.2011.05.010

Noorhisham, T. K., Norliza, A. R., \& Sobri, M. T. (2009). Independent learning via open ended laboratory assignment: JKKP experience. Proceeding for PEKA 'Seminar Pendidikan Kejuruteraan \& Alam Bina (PeKA2009)', 14-16 Dec 2009, Langkawi, 89-95.

Norliza, A. R., Noorhisham, T. K., Sobri, M. T., \& Siti Rozaimah, S. A. (2011). Comparative study between open ended laboratory and traditional laboratory. IEEE EDUCON Education Engineering 2011 - Learning Environments and Ecosystems in Engineering Education, 1-5

Sanguinetti, J. (2004). Generic skills for employability: Educational colonisation or educational opportunity? Article for AARE, Australia.

Thomas, P. S., Fernandez, R. F., \& Manjon, B. F. (2009). Learning team work skills in university programming courses. Computer \& Education, 53, 517-531. http://dx.doi.org/10.1016/j.compedu.2009.03.010

Webb, C. (2007). Assessor report for biochemical engineering programme (Department of Chemical \& Process Engineering, Faculty of Engineering \& Built Environment, Universiti Kebangsaan Malaysia). 